\title{
RESPONDING TO CHEMICAL INCIDENTS - A RURAL PERSPECTIVE
}

Neil Stubbs, Community Services Manager, Council of the City of Wagga Wagga

(formerly Senior Environmental Health Officer

South West Public Health Unit)

Tony Kolbe, Director

South West Centre for Public Health

\section{INTRODUCTION}

The involvement of Public Health Unit (PHU) staff in the response to chemical spills, including those caused by motor vehicle accidents, has been under discussion for some time. It is particularly relevant to rural PHUs because motor vehicle accidents are not uncommon on the network of highways throughout NSW. Although PHUs operate on an on-call basis, they are not a 24 -hour "combat agency". Attending an incident may involve considerable travelling time and leave an officer isolated at the site with limited access to data and less than adequate communication facilities. Attempts at arranging the notification of incidents by police and ambulance control networks have generally been unsuccessful. The question arises as to the role of PHU staff both at the site of the incident and otherwise and how a PHU might best carry out its responsibilities.

A recent incident has highlighted the value of PHU involvement. It has also provided a practical example to trial a methodology for response to a chemical incident.

\section{THE INCIDENT}

About 0300 hours on Wednesday, July 7, 1993 a 30,000 litre tanker was involved in a motor vehicle accident on the Hume Highway 10 kilometres north of Gundagai. As a result of the rupture of one compartment, about 2,000 litres of the liquid formaldehyde ( $37 \%$ solution) was discharged from the tanker. Emergency services on site attempted to contain the spill, but heavy rainfall at the time meant this was unsuccessful and the liquid entered a creek which discharged into the Murrumbidgee River.

Formaldehyde solution (other names: formalin, formol, methanol solution $37 \%$ ) is a general chemical used in resin manufacture and as a preservative. The material is a clear, colourless liquid with a pungent, irritating odour. It is miscible in water. The material is a powerful reducing agent which reacts with acids, bases and metal salts. If swallowed it can cause nausea, vomiting, diarrhoea, abdominal pains and loss of consciousness. The material can irritate the eye, skin and mucous membranes. Long-term animal test data suggest a carcinogenic potential. The Draft Revised Drinking Water Standards recommends that the formaldehyde concentration in drinking water should not exceed $0.5 \mathrm{mg} / \mathrm{L}$ while the World Health Organisation guideline value is $0.9 \mathrm{mg} / \mathrm{L}$.

Rainfall in the area for the day of the incident and those either side of it was $16-31 \mathrm{~mm}$. All watercourses were flowing well and "good" dilution was expected.

Wagga Wagga and Gundagai Fire Brigades and an Environment Protection Agency (EPA) officer attended the site. The PHU learned of the incident only from media reports at 0900 hours.

\section{ACTION TAKEN}

- Initial contact was made to the site NSW Fire Brigades Zone Commander's mobile telephone and a verbal assessment of the situation was obtained. Contact was made with Epidemiology Branch and toxicological information requested. This was received by facsimile.
- Contact was made with the local council's Shire Clerk and it was suggested that precautionary steps be considered to protect the water supply. Contact was also made with the NSW Police Patrol Commanders, Wagga Wagga and Gundagai. Links were established through the District Emergency Management Committee by the Divisional Controller of the State Emergency Services (SES). It was decided that the SES would handle media liaison.

Based on this advice, the unknown health effects, dilution rates and mixing within the river, it was decided to act conservatively and take the following action:

- fill the town reservoirs in the time available; and - shut down the water supply system before the expected arrival of any chemical and not restart the plant until residuals would have passed.

Contact was received from the Emergency Response Unit of the manufacturing chemical company. Advice on action taken by both organisations was exchanged. Safety data sheets were supplied to the PHU by facsimile.

- Contact was made with the SES Divisional Controller and a briefing minute was provided to help prepare a media release. The public health risks were considered to be low to moderate, but until water sample results were received it was decided to act conservatively and advise that water below the accident site should not be used for drinking, domestic or stock purposes until further notice and that any water pumped from the time of the accident be discarded.

Contact was made with the Southern Riverina County Council, the water supply authority for Wagga Wagga and environs. In consultation with engineering staff, it was decided that the supply should be protected, again primarily as a precautionary measure. The authority decided to shut down the river component of the supply system and rely totally on the bore system to accommodate the passage of any residuals. Subsequent testing indicated $1.1 \mathrm{mg} / \mathrm{L}$ of formaldehyde at entry to Muttama Creek and "none detected" at Gundagai with a testing detection limit of $0.2 \mathrm{mg} / \mathrm{L}$. An adjacent farm dam contaminated by the spill contained $250 \mathrm{mg} / \mathrm{L}$.

\section{DISCUSSION}

A response procedure model had been under development for some time for the area covered by the South West Centre for Public Health. Contacts had been made with the Zone Commander, NSW Fire Brigades, Zone 4 for a co-operative approach between the organisations for such incidents. The procedural and action steps would include:

The PHU out-of-hours contact system would be included in the operational protocol for chemical incidents at the Albury and Wagga Wagga Fire Stations.

On receipt of an alert, the duty public health officer would contact the appropriate control room at Albury or Wagga Wagga Fire Station (which between them cover the South West District) by telephone to obtain further data on the incident. 
$\square \quad$ If appropriate, the officer would go to the control room to provide public health advice and receive data through the Fire Brigades' communication system. The decision to go to the control room would depend on an assessment of each incident. Once the nature of the situation is clear and adequate toxicological data are available, a decision could be made about sending an officer to the scene of the incident.

The perceived advantages of the system are that:

$\square \quad$ scarce resources are conserved;

$\square$ the trained staff are kept close to developed communications resources; and

the staff can better gather toxicological data if they have access to telephones, fax machines, the resources of Epidemiology Branch and the chemical company concerned.

The incident involving formaldehyde has indicated the model may have potential for further development.

\section{EDITORIAL COMMENT}

This report highlights the need for a rapid response and timely access to health information, as well as the need for early notification of chemical incidents to local public health authorities.

A protocol for public health response to chemical incidents was developed and approved by the NSW Health Department in 1992 to provide a systematic approach to the investigation of incidents by PHUs. However, the remote locations of some incidents may require modifications of the protocol, and so feedback from the PHUs is necessary to improve its practicability. Nevertheless, this report underlines the importance of the use of a standardised method for responding to incidents.

The protocol presents a framework for:

- deciding the type of incidents which should be investigated by PHUs; conducting a rapid health impact assessment of an incident. The checklist provides a structured method of collecting information and is based on an adaptation of a WHO checklist. When finalised, the computerised standard format should be used for reporting;

liaising with other combat agencies such as fire brigade, the police, and the Environment Protection Authority to obtain relevant health information;

collecting and having access to key information at the time of the incident, to enable the assessment of the chronic, as well as the acute, health effects of an incident. This may include information on the nature of the chemical, its concentration in the environment, prevailing weather conditions, the likely spread of the chemical and the population at risk of exposure to the chemical; and

determining the need for long-term follow-up of people affected in a chemical incident.

Faster notifications and better access to appropriate toxicological data would improve the existing system. The reporting by each Public Health Unit of chemical incidents in a standardised manner will also help paint a State-wide picture of the health impact of chemical incidents in NSW.

\section{NEWS AND COMMENT}

\section{HIV DATA QUALITY}

The editor has received a letter from Professor David Cooper, Director, St Vincent's Hospital (SVH) Centre for Immunology HIV reference laboratory, concerning the editorial comment to the article, "Improving the quality of HIV Data" (Public Health Bulletin, January 1994; 5:10-11). The letter expresses concern that the editorial comment contained unwarranted criticism of the data quality from SVH laboratory.

\section{Editor's comment}

Any perceived criticism of the data quality from SVH laboratory was not intended. Data analysis carried out by the Epidemiology Branch shows that data from both Prince of Wales and SVH HIV laboratories are of an equally high standard. We would like to stress that the callback procedure was implemented in all HIV reference laboratories in 1992 resulting in a substantial improvement in data quality. The point of the editorial comment was that, in response to the recent suspected case of patient-to-patient HIV transmission, the Department: (a) has restated the need for high quality data on risk exposure, and (b) will carry out follow-up surveillance where appropriate.

\section{UNLEADED PETROL DISCUSSION CONTINUES}

Dr Donald Scott-Orr has written to say he is at Comboyne, north of Taree, NSW, and not in London as we published in the February Public Health Bulletin.

His letter continues: "The response from the authors, to my comments on their November 1993 article on the virtues of unleaded petrol, was useful. However, they do not address the issue of need for a catalytic converter.

In Australia, since those cars required to use unleaded petrol should also have converters, "the low levels of benzene found in ambient air in Australian cities may depend partly on this and the low conversion rate to unleaded petrol in those earlier cars which can use leaded and unleaded.

If the converters were thought to be necessary here and earlier car users are now encouraged to make use of unleaded petrol (without converters), ever though its octane rating is lower than in Europe, is there not a greater potential carcinogenic hazard than the authors suggest?

Perhaps the authors, and the Lead in Petrol Working Group, would also comment on the current availability of (higher priced) higher octane rated unleaded petrol and the concomitant encouragement of its use.

When Neville Wran was premier some people may have believed his promise that unleaded petrol would become and remain cheaper than leaded - to encourage the use of unleaded. Now the proposal is to increase the price of leaded for the same purpose. Let us hope that some of the revenue will enhance research into alternatives."

\section{ERRATUM}

Public Health Bulletin, January 1994; 5:5 -

Boom in demand for genetics services in NSW

It should be noted that Statewide cytogenetics services are provided from laboratories located at Prince of Wales Hospital, Royal Alexandra Hospital for Children, Royal North Shore Hospital, Westmead Hospital and John Hunter Hospital. Statewide molecular genetics services are provided from three laboratory groups: Prince of Wales Hospital/ Concord Hospital, Royal Prince Alfred Hospital/Royal North Shore Hospital and John Hunter Hospital. 